\title{
Research on the Optimization of MBA Course "Management Communication" in Universities of Science and Engineering Under the Background of Double First-Class Construction: A Case Study of Central South University
}

\author{
Hui Tian*, Jiahuan Wang, Huachen Pan
}

Business School, Central South University, Changsha, China

*Corresponding author. Email: tita0322@163.com

\begin{abstract}
On the basis of combing the relevant research fruits, taking Central South University for example, this paper analyzes the current situation of MBA course "management communication" from three aspects: the characteristics of the course, the problems existing in the course construction and the reasons for these problems, based on which, combining the requirements for "Double-first-class" construction, this paper puts forward the optimized paths of MBA "management communication" course under the background of "Double-first-class" construction from the four aspects of curriculum characteristics, teaching mode, the construction of teaching teams and fund guarantee.This paper is expected to provide reference for Science and Engineering Universities to build high-quality humanities courses with cutting-edge and characteristics, and to give guidance for the construction of "Double First-class" courses in science and engineering universities.
\end{abstract}

Keywords: Double first-class, Management communication, University of science and engineering, MBA, Curriculum construction.

\section{“双一流”背景下理工科大学MBA《管理沟通》课程优 化研究一以中南大学为例}

田晖*，王佳欢，潘华晨

中南大学商学院, 长沙市, 中国

*通讯作者. 邮箱: tita0322@163.com

\section{中文摘要}

在梳理相关研究成果的基础上, 以中南大学为例, 从课程特点、课程存在的问题及原因三方面, 深入分析 MBA

《管理沟通》课程现状，并在此基础上，结合“双一流”建设要求，从课程特色、教学模式、师资建设和资金保 障四方面，提出“双一流”背景下 MBA 《管理沟通》课程的优化路径，以期为理工科大学打造兼备前沿性和特 色性的高质量的人文类课程提供借鉴，为促进理工科大学“双一流”课程的建设提供指导。

关键词: 双一流，管理沟通，理工科大学， $M B A ，$ 课程建设 


\section{1. 前言}

2017 年 9 月 21 日, 教育部、财政部、国家发改委 印发《关于公布世界一流大学和一流学科建设高校及 建设学科名单的通知》, 公布了世界一流大学和一流 学科 (简称“双一流”) 建设高校及建设学科名单, 为 中国高校培养人才的模式提出了新要求。“双一流”建 设方案将一流大学的建设和一流学科的建设并重, 以 每五年为建设周期进行动态调整, 突出绩效导向[1]。 在“双一流”的背景下, 高校需要更着重于优质学科的 建设, 挖掘出其自身的内在潜能, 是打造优质学科的 重要保证。

中南大学于 2017 年 9 月入选世界一流大学 A 类建 设高校。在“双一流”建设之前, 像中南大学这样的理 工院校大都注重原有优势专业的发展, 讲究学科的覆 盖面而不是学科质量。例如, 2015 年, 中南大学硕 士点达到 62 个, 学科覆盖齐全, 但就一级博、硕士 点数量而言, 人文社科专业占比仅为 $15.2 \%$ 。2020 年 的最新数据显示, 中南大学人文社科一级博、硕士点 的占比已经提高到 $21.2 \%$ 。2015 年中南大学人文类学 科发展精度较低, 导致像《管理沟通》之类的人文社 科课程发展后劲不足, 无法适应“双一流”建设的现实 需求。在“双一流”建设推进之后, 中南大学进一步优 化了学科发展战略, 在发展优势理工专业的同时加强 对人文社科专业的扶植, 使得学科精度大幅提高, 为 MBA 《管理沟通》课程的建设提供了有利的条件。 鉴于此, 本文以中南大学为例, 重点探讨商学院 MBA 《管理沟通》课程优化问题, 旨在为提升中南大学商 学院 MBA《管理沟通》课程质量提供可行的思路, 为理工科院校打造 “双一流” 优质人文社科课程提供 有益的借鉴。

\section{MBA《管理沟通》课程建设现存问题: 以 中南大学为例}

自 2015 年国务院发布了《统筹推进世界一流大 学和一流学科建设总体方案》 (以下简称“方案”) 、 明确提出“双一流”战略布局以来, 全国高校纷纷开展 了双一流建设。其中, “方案”明确要求高校要建设一 批能够培养出具有历史使命感和社会责任心、且富有 创新精神和实践能力的各类创新型、应用型、复合型 优秀人才的、兼备前沿性和特色性的高质量课程, 同 时要求高校打造一流师资队伍、着力协调校内外资源 并推进教学成果转化。然而, 作为 MBA 教育的核心 课程之一, 《管理沟通》课程目前仍然存在着课程体 系与时代脱轨、课程特色不够、资源整合不到位、经 费投入不足等一系列问题, 且对于像中南大学这样偏 理工科的综合性大学来说, 这些问题尤为明显, 具体 体现以下几方面:

\section{1. 课程末体现出理工科院校的特色}

MBA 教育在大部分理工科院校的起步时间较晚, 发展远不如理工类学科强势。同时, 由于传统的“重
理轻文”等观念的影响, 大部分理工科院校对 MBA 教 育发展定位不明确, 战略目标模糊, 使得这些院校的 MBA 教育既缺少理工科大学的特色, 又缺乏专业财 经院校及综合性大学的竞争优势[2]。此外, 理工科院 校注重实业教育, 自主创业的学生较多, 拥有丰富的 企业资源, 本应该是理工科大学的优势所在。然而, 目前中南大学 MBA《管理沟通》课程设置仍然沿用 传统学术类型的硕士研究生的课程体系, 并没有利用 校企资源帮助学生提高实战演练能力, 且现有校企合 作的深度和广度还不够, 使 MBA《管理沟通》课程 建设未充分体现理工科大学实业教育带来的特色优 势。

\section{2. 现有课程体系与时代脱轨}

《管理沟通》作为外来课程, 其教材目前以照搬 外国教材为主, 由于忽略了中西方文化差异, 现有的 MBA 《管理沟通》课程的外文教材不适用于中国情 景, 课上所讲授的案例过于陈旧, 未能紧贴时代主题, 从而无法引起学生的共鸣[3]。此外, 现今的考核制度 仍偏向期末的一考制, 重理论轻能力, 严重与时代脱 轨。

与此同时, 随着“大众创业、万众创新”战略的持 续推进, 深化创新创业教育成为高校顺应时代潮流、 促进“双一流”建设的必然选择。《管理沟通》作为一 门实操性强的课程, 更需要紧跟时代脉搏。然而很多 理工科院校没有及时地将双创教育融入 MBA《管理 沟通》课程体系, 仍采用“理论为主, 实践为辅”的教 学方法, 忽视了创新创业情景下的沟通实战演练, 使 学生无法将所学的知识应用到真实的场景中, 教学目 标难以实现, 教学效果也大打折扣。

\section{3. 课程教学资源整合不够}

目前中南大学 MBA《管理沟通》课程中, 既拥有 扎实的理论知识又拥有丰富的实践经验的教师资源 十分欠缺。作为一门综合性较强的课程, 《管理沟通》 要求任课教师具备广博的理论知识和丰富的实践经 验。而现实情况是, 管理沟通领域兼备“理论知识”与 “实战经验”的教师资源十分欠缺, 大部分教师成长于 传统的理论式教学环境中, 缺乏相应的实践经验, 要 将理论和实践完美结合起来, 还有很长的路要走。

同时, 校外教学资源未能被充分利用。如今, 包 括中南大学在内的许多高校都培养了很多优秀的企 业精英, 他们积累了丰富的实战经验, 在创新创业方 面有独到的见解, 完全可以担任 MBA 学生的校外导 师, 参与课程的开发和教学, 同时还能为学生提供实 践平台。遗憾的是, 这些高校却并没有将宝贵的企业 资源充分转化为教学资源。 


\section{4. 教学和科研经费投入不足, 课程发展后劲 不够}

对于实操性较强的 MBA《管理沟通》课程来说, 需要学校、学院有足够的教学和科研经费来为学生提 供优质的课程资源, 以此支撑课程体系的不断发展和 完善。然而, 很多理工科高校, 一直将理科、工科作 为重点发展的优势学科, 在人文社科专业上的经费投 入远远少于本校优势的理工专业, 这就导致《管理沟 通》课程本身资源支撑不足, 课程发展也缺少后劲, 最终产生“马太效应”。这种由于内部资源分配不协调 而导致整体发展不均衡的现象不仅会影响高校整体 的发展和口碑, 还不利于高校推进“双一流”建设, 因 此亟需得到解决。

\section{3. “双一流”背景下理工科大学 MBA《管理沟 通》课程优化路径}

“双一流”建设方案的提出为国内高校提供新的发 展思路, 也为优化现有 MBA 《管理沟通》课程提供 指南。就中南大学而言, 应在保持原有理工科优势的 同时，加大对《管理沟通》之类的人文社科类课程的 扶持和建设; 其次, 利用“双一流”建设的契机, 加强 学科差异化、特色化发展, 并将自身的优势和特色与 《管理沟通》课程相结合, 整合校企资源, 建立具有 理工科院校特色的 MBA《管理沟通》课程体系。具 体而言, 应从以下几方面优化 MBA《管理沟通》课 程:

\section{1. 发挥理工科院校优势, 优化具有院校特色 的 MBA 《管理沟通》课程体系}

“双一流”要求高校以学科为基础, 引导和支持高 等学校优化学科结构, 凝练学科发展方向, 突出学科 建设重点, 带动学校发挥优势、办出特色。为了满足 “双一流”建设对 MBA《管理沟通》课程提出的新要 求, 一方面, 中南大学应调整传统的学术类型的硕士 研究生课程设计思路, 将教学重心放到学生自主实践 上, 在课程教学中添加实战训练部分, 利用理工科高 校具备丰富的校友资源的优势, 搭建校企实践合作平 台, 增强校企合作的深度和广度; 另一方面, 借助学 校的王牌专业, 在高校特色交叉学科中大力推广《管 理沟通》课程, 将强势学科的优势融入到管理沟通课 堂中，开发适合不同行业的《管理沟通》课程。

中南大学的王牌专业有材料、治金、医学等, 可 以将这些学科特色优势融入《管理沟通》课程中。 MBA 《管理沟通》责任教授可以联合本校材料、冶 金、医学领域资深教授, 开发适合不同行业人才的《管 理沟通》课程, 如针对冶金类企业与医疗企业 MBA 学员的《管理沟通》课程侧重点应有所区别。这种融 入学校特色优势的个性化课程不仅能促进不同学科 的交叉融合，还有利于实现“方案”提出的主要目标。

\section{2. 丰富课堂教学模式，提升 $M B A$ 《管理沟 通》教学质量}

目前，国内高校《管理沟通》课程教学多采用“知 识讲授+课堂教学, 让学员讲授案例等实践环节”的传 统教学模式[4], 没能调动学员学习积极性和主动性, 致使他们无法应对复杂经济环境下的管理沟通问题。 为了避免这种问题的出现，应合理分配《管理沟通》 的课程教学课时。除了基本的课程讲授时间外, 还要 增加学员自己编写案例和在课堂讨论案例的时间及 情景模拟、角色扮演等可以让学生进行沟通实训的时 间 [5]。除了基本的教学外, 还可以采取过程考核占比 $80 \%$,结果考核占比 $20 \%$ 为主要依据的考核方式来优 化考核制度, 加大过程考核在整体考核中的占比。再 次,在 MBA 教学内容的选择上应注重培养学员的综 合素质和能力, 特别是学员的领导能力、协调沟通能 力、创造力、团队合作精神以及良好的商业伦理的培 养, 积极调动学生的主观能动性, 培养适应时代要求 的各类创新型、应用型、复合型优秀人才。

\section{3. 打造一流教师队伍, 为 $M B A$ 《管理沟通》 课程教学提供师资保障}

作为以理工科见长的高校, 中南大学商学院内既 拥有扎实的理论知识又拥有丰富的实践经验条件的 教师资源十分欠缺。“双一流”建设任务要求学校要打 造一流的师资队伍, 遵循教师成长发展规律, 培育跨 学科、跨领域的创新团队，增强人才队伍可持续发展 能力。因此, 中南大学应当积极进行校内外资源整合, 想方设法引进领军人才, 主张教师深入企业从事研究, 加强与企业界人士的沟通交流[6], 还可以邀请优秀的 企业界人士参与到课堂中来, 举办优秀企业家论坛等 专题活动, 有条件的院校还可以聘请优秀企业家来校 举办讲座等活动, 提高课程教学的实用性。

\section{4. 利用政府、企业及学校的资源, 为 $M B A$ 《管理沟通》课程教学提供资金保障}

“双一流”建设建议高校进一步增强财务自主权和 统筹安排经费的能力, 充分激发高校争创一流、办出 特色的动力和活力。为此, 中南大学应当平衡校内资 金投入，为《管理沟通》等非传统优势课程优化提供 坚实的资源保障，构建良好的 MBA《管理沟通》课 程体系, 另一方面, 要充分利用政府政策及社会资源, 为《管理沟通》课程发展提供政策、资金、技术等方 面的保障, 通过政产学研合作，对各种教育资源进行 重新组合和共享，形成更加强大的资源协同优势。

综上, “双一流”背景下理工科大学 MBA《管理沟 通》课程优化路径具体如下图所示: 


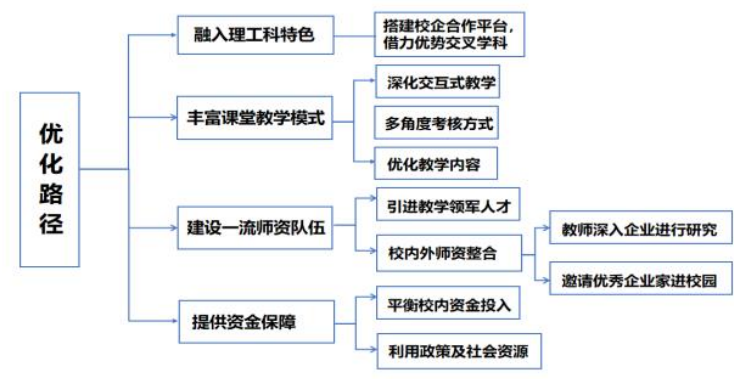

图 1 “双一流”背景下理工科大学《管理沟通》课程优 化路径

\section{4. 结语}

“双一流”的提出彰显了我国建设世界一流大学的 决心,也给全国各地各层次高校的学科发展营造了良 好氛围、指引了前进方向[7]。在“双一流”的建设要求 下, 理工科高校应不断优化像 MBA《管理沟通》这 样的人文社科类课程体系, 在结合理工科院校的特色 创新课程内容的同时, 注重优秀教师队伍的打造, 不 断提高人才培养质量、提升科学研究水平, 形成积极 向上、质量优先的学科文化, 进而积极推动兼备世界 一流水平、中国特色、理工风格的人文社科类学科的 建设与发展。这样的举措不仅能够为国家高等教育的 发展做出应有的贡献, 最终也能助推“双一流”建设, 形成“以特色课程拉动学科发展, 以优秀学科滋养课 程”的良性循环。

\section{致谢}

基金项目：2019 年湖南省学位与研究生教育改革 重点研究项目—— “双一流” 背景下中南大学 MBA 管理沟通课程体系建设研究 (2019JG009)

\section{REFERENCES}

[1] Graduate School of Central South University. Central South University's 2016Master's Admissions Guide [EB/OL].(2019-09-16)[2020-08-15].http://gra.csu.e du.cn/wjtzxq102631_1_2.html.

[2] $\mathrm{Na} \mathrm{Xu}$, Xin Hua.On the Cultivation of Economic Innovation Talents in University of Science and Technology[J]. China Education of Light Industry,2009(03):14-17.

[3] Wei Xie. Research on the curriculum reform of "Management Communication" based on professional ability orientation. Knowledge Economy, 2016(14): 177-178.

[4] Shenghua Yang. Talk about the reform of the teaching method of the "Management Communication" course in colleges and universities[J]. Education, 2012(9):123-123.
[5] Strayer J. How learning in an inverted classroom influences cooperation, innovation and task orientation[J]. Learning Environments Research,2012,15(2).

[6] Huizhong Xu, Jie Zhang. Development of MBA "Management Communication" Course[J]. Degree and Graduate Edu cation, 2001(06): 21-23.

[7] Xue Han, Thoughts on Disciplinary Construction in Colleges and Universities under the Background of "Double First-class", Education Modernization 2020,7(46),100-103. 